\title{
Bronchoscopy findings in invasive pulmonary aspergillosis
}

\section{H VEREA-HERNANDO, M T MARTIN-EGAÑA, C MONTERO-MARTINEZ, J FONTAN-BUESO}

\author{
From the Pulmonary Unit, Hospital "Juan Canalejo," La Coruña, Spain
}

ABSTRACT Two patients with invasive aspergillosis had unusual endobronchial appearances at fibreoptic bronchoscopy. Diagnosis was achieved by endobronchial biopsy.

Fibreoptic bronchoscopy is used to diagnose infections in immunocompromised patients. The samples taken are usually bronchial washings and brushings, bronchoalveolar lavage fluid, or transbronchial biopsy material. Diagnosis of invasive aspergillosis is rarely achieved by biopsy of visualised bronchial lesions.'

We report two patients with invasive aspergillosis whose bronchial tree showed particular features that led to diagnosis of the infection.

\section{Case reports}

\section{PATIENT 1}

A 48 year old retired quarryman, a smoker, was treated for pulmonary tuberculosis in 1981 and presented in 1982 with malaise and polyarthritis. Subluxation and joint destruction were present in both hands. Antinuclear antibodies were present at a titre of 1:10244 with a homogeneous pattern and antibodies to double stranded DNA at a titre of 1:320, and the lupus erythematosus cell test gave a positive result. Rheumatoid factor and extractable nuclear antigens were undetectable; other criteria for the diagnosis of systemic lupus erythematosus were not met. His condition improved after treatment with prednisone.

In 1986 he presented with progressive weakness, anorexia, weight loss, fever, and haemoptysis. He had received treatment with chloroquine alone for the previous 12 months. The white blood cell count was $9.06 \times 10^{9} / 1$ with $73 \%$ neutrophils. Antinuclear antibodies were present at a titre of 1:1280; antibodies to double stranded DNA were not detected. The chest radiograph showed an irregular nodular infiltrate in the right upper lobe, segmental consolidation in the left upper lobe, and slight paratracheal lymphadenopathy (fig 1). Fibreoptic bronchoscopy showed brownish, jelly like, cone shaped excrescences in the distal trachea (fig $2 a$ ) and in the openings of both upper lobe bronchi. Biopsy of this material showed granulation tissue and septate hyphae. Aspergillus fumigatus was cultured; anaerobes, aerobes, and mycobacteria were not isolated. Serum aspergillus precipitins were

Address for reprint requests: Dr Hector Verea-Hernando, Sección de Neumologia, Hospital "Juan Canalejo," La Coruña, Spain.

Accepted 9 May 1989 detected. He was treated with amphotericin $B$ to a total dosêे of $1700 \mathrm{mg}$, but neurological, ophthalmological, and cardia complications ensued and the patient died.

Necropsy showed a left upper lobe, necrotic, aspergillus pneumonia affecting also the mediastinum. Mediastinado lymph nodes were discharging into the trachea and bronchuș Fungal invasion of the heart, aorta, kidneys, spleen, and central nervous system was seen. Scattered coniotic micro? nodules in the lung and a large embolus in the right pulmonary artery were also found.

\section{PATIENT 2}

A 26 year old man receiving chemotherapy for lymphoblastic leukaemia was admitted because of fever and a segmentabo infiltrate in the left upper lobe. The granulocyte count was $0.31 \times 10^{9} / 1$. After seven days' treatment with ticarcillin an tobramycin, the shadowing on the chest radiograph has increased, though there was no cavitation. His fever persisted and amphotericin B was started. The granulocyte count wao $3.2 \times 10^{9} / 1$ and the platelet count $165 \times 10^{9} / 1$. At fibreoptio bronchoscopy an eroded bronchial wall was seen at the lefe superior division (fig $2 b$ ) and at the lingular bronchus Through one of the ulcers the bronchoscope tip entered an empty, black walled cavity. Biopsy of the wall showed septate hyphae and Aspergillus fumigatus was cultured. The patient died 36 hours later from a massive haemoptysis.

At necropsy aspergillus necrotising pneumonia was found in the left upper lobe with spread to the heart, kidneys, and thyroid gland.

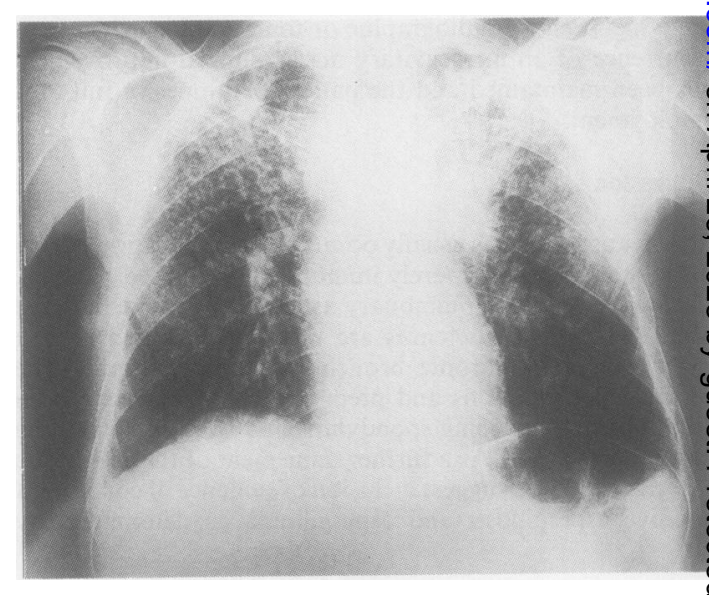

Fig 1 Chest radiograph for patient 1. 



Fig 2 (a) Polypoid lesions in the trachea of patient 1. (b) Ulcer of the bronchial wall and necrotic cavity (arrow). On the left is the opening of the B1 and B2 bronchi and at the top the $B 3$ bronchus.

\section{Discussion}

In invasive aspergillosis the bronchi are less frequently colonised than the parenchyma ${ }^{2}$ and bronchoscopic findings have been reported infrequently.' The first patient had endobronchial lesions resembling perforation from contiguous lymph nodes, which was later confirmed. Segmental mucosal lesions of the trachea with paratracheal soft tissue inflammation and no mediastinal lymphadenopathy have been found by computed tomography. ${ }^{3}$ Two other cases presented with large airways obstruction by fungal plugs but mediastinal invasion was not documented. ${ }^{4}$

Fatal haemoptypsis, as occurred in the second patient, has been reported in invasive aspergillosis. Lung necrosis may develop in patients with pulmonary aspergillosis recovering from granulocytopenia induced by chemotherapy, ${ }^{5}$ as in our case. This happened also in a patient with a bronchial ulcer and a broncho-oesophageal fistula. ${ }^{6}$ We were able to visualise a pulmonary cavity, which could represent an early stage of a "mycotic lung sequestrum." This bronchial lesion suggests the need to consider surgical resection, as proposed by Kibbler et al. ${ }^{\text {? }}$

The bronchial biopsy specimens from our two patients showed tissue invasion by fungus but no colonisation of blood vessels, as reported by Chung et al, ${ }^{8}$ who used transbronchial biopsy. The particular endoscopic findings in our cases led us to start treatment with amphotericin B and invasive aspergillosis was confirmed at necropsy.

\section{References}

1 Albelda SM, Talbot GH, Gerson SL, Miller WT, Cassileth PA. Role of fibreoptic bronchoscopy in the diagnosis of invasive pulmonary aspergillosis in patients with acute leukemia. Am J Med 1984;76:1027-34.

2 Young RC, Bennett JE, Vogel CL, Carbone PP, De Vita VT. Aspergillosis. The spectrum of the disease in 98 patients. Medicine (Baltimore) 1970;49:147-73.

3 Vail CM, Chiles C. Invasive pulmonary aspergillosis: Radiologic evidence of tracheal involvement. Radiology 1987;165:745-6.

4 Baud M, Chevrolet JC, Dusmet M, Junod AF. Aspergillose avec obstruction des voies aeriennes centrales. Schweiz Med Wochenschr 1986;116:1316-8.

5 Albelda SM, Talbot GH, Gerson SL, Miller WT, Cassileth PA. Pulmonary cavitation and massive hemoptysis in invasive pulmonary aspergillosis. Am Rev Respir Dis 1985;131:115-20.

6 Mineur PH, Ferrant A, Wallon J, Otte JB, Michaux JL. Bronchoesophageal fistula caused by pulmonary aspergillosis. Eur $J$ Respir Dis 1985;66:360-6.

7 Kibbler CC, Milkins SR, Bhmra A, Spiteri MA, Noone P, Prentice HG. Apparent pulmonary mycetoma following invasive aspergillosis in neutropenic patients. Thorax 1988;43:108-12.

8 Chung C, Lord PL, Krumpe PE. Diagnosis of invasive pulmonary aspergillosis by fiberoptic transbronchial lung biopsy. JAMA 1978;239:749-50. 